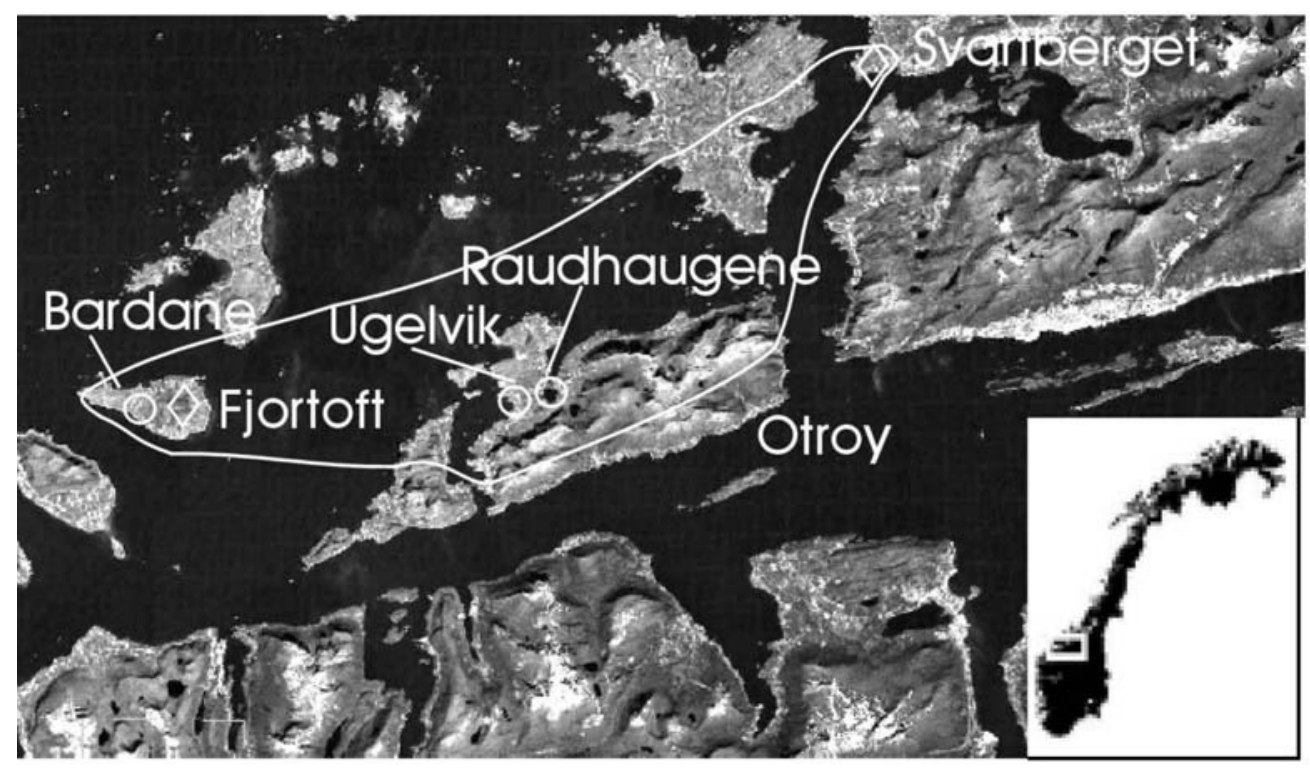

Figure DR1. Satellite view of the Fjørtoft and Otrøy islands and the Bardane, Raudhaugene, Ugelvik and Svartberget localities (WGR, Norway). Open circle = majorite; open diamond $=$ diamond. The solid white line outlines the northernmost UHP domain in the WGR. Inset shows this area in Norway.
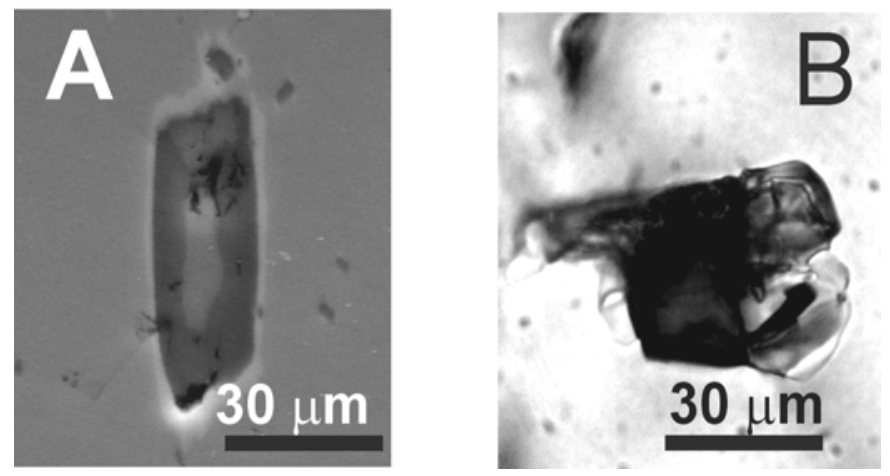

Figure DR2 . A: Carbonate inclusion inside coarse M2 opx. Light grey core: dolomite, intermediate dark grey rim: magnesite, light outermost rim: cpx, host: opx. B: Mulitphase solid inclusion with sp, phl and px inside the M3 majoritic grt. 
Table DR1. Average EPMA analyses of M3 minerals.

Scambelluri et al., p. 2

\begin{tabular}{|c|c|c|c|c|c|c|c|c|c|}
\hline & 1 & 2 & 3 & 4 & 5 & 6 & 7 & 8 & 9 \\
\hline & M3 cpx & M3 cpx & M3 opx & M3 grt & M3 grt & M3 phl & M3 grain bd mj & M3 vein mj & M1-M2 mj \\
\hline & $\begin{array}{l}\text { exs in grt } \\
11\end{array}$ & grain bd & grain bd & $\underset{9}{\text { grain bd }}$ & vein & grain bd & 1.5 vol\% px & & 20 vol \% px \\
\hline $\mathrm{SiO} 2$ & 53.71 & 56.12 & 57.29 & 42.00 & 41.96 & 38.54 & 42.19 & 42.32 & 45.51 \\
\hline $\mathrm{TiO} 2$ & 0.34 & 0.13 & 0.10 & 0.12 & 0.07 & 3.71 & 0.11 & 0.11 & 0.08 \\
\hline $\mathrm{Cr} 2 \mathrm{O} 3$ & 3.36 & 1.36 & 0.36 & 3.55 & 3.35 & 2.26 & 3.28 & 3.58 & 1.09 \\
\hline $\mathrm{A} 12 \mathrm{O} 3$ & 5.69 & 2.21 & 1.29 & 21.38 & 21.73 & 16.41 & 21.05 & 21.22 & 18.99 \\
\hline $\mathrm{FeO}$ & 1.55 & 2.48 & 4.92 & 8.67 & 8.16 & 2.36 & 8.17 & 8.48 & 5.00 \\
\hline $\mathrm{MnO}$ & 0.10 & 12.08 & 0.17 & 0.49 & 0.44 & 0.12 & 0.47 & 0.59 & 0.16 \\
\hline $\mathrm{MgO}$ & 13.95 & 10.31 & 35.58 & 19.22 & 19.35 & 21.65 & 19.66 & 19.41 & 21.05 \\
\hline $\mathrm{CaO}$ & 17.98 & 13.84 & 0.26 & 5.18 & 5.28 & 0.08 & 5.38 & 5.06 & 7.90 \\
\hline $\mathrm{Na} 2 \mathrm{O}$ & 3.46 & 1.55 & 0.03 & B.D. & B.D & 0.34 & 0.03 & 0.05 & 0.34 \\
\hline $\mathrm{K} 2 \mathrm{O}$ & 0.03 & 0.05 & 0.04 & B.D & B.D & 9.86 & B.D & B.D & B.D \\
\hline $\mathrm{H} 2 \mathrm{O}$ & 0.00 & 0.00 & 0.00 & 0.00 & 0.00 & 4.27 & 0.00 & 0.00 & 0.00 \\
\hline Total & 100.17 & 100.12 & 100.05 & 100.61 & 100.35 & 99.61 & 100.34 & 100.82 & 100.11 \\
\hline $\mathrm{Si}$ & 1.93 & 1.98 & 1.96 & 3.00 & 3.00 & 2.71 & 3.01 & 3.01 & 3.20 \\
\hline $\mathrm{Ti}$ & 0.01 & 0.00 & 0.00 & 0.01 & 0.00 & 0.17 & 0.01 & 0.01 & 0.00 \\
\hline $\mathrm{Cr}$ & 0.10 & 0.04 & 0.01 & 0.20 & 0.19 & 0.12 & 0.19 & 0.20 & 0.06 \\
\hline $\mathrm{Al}$ & 0.24 & 0.09 & 0.05 & 1.80 & 1.83 & 1.39 & 1.77 & 1.78 & 1.57 \\
\hline $\mathrm{Fe} 2$ & 0.05 & 0.07 & 0.14 & 0.52 & 0.49 & 0.14 & 0.49 & 0.50 & 0.29 \\
\hline $\mathrm{Mn}$ & 0.00 & 0.61 & 0.01 & 0.03 & 0.03 & 0.01 & 0.03 & 0.04 & 0.01 \\
\hline $\mathrm{Mg}$ & 0.75 & 0.55 & 1.82 & 2.05 & 2.06 & 2.30 & 2.09 & 2.06 & 2.21 \\
\hline $\mathrm{Ca}$ & 0.69 & 0.53 & 0.01 & 0.40 & 0.40 & 0.01 & 0.41 & 0.38 & 0.60 \\
\hline $\mathrm{Na}$ & 0.24 & 0.11 & 0.002 & - & - & 0.04 & 0.004 & 0.01 & 0.05 \\
\hline $\mathrm{K}$ & 0.001 & 0.002 & 0.002 & - & - & 0.89 & - & & - \\
\hline $\mathrm{OH}$ & 0.00 & 0.00 & 0.00 & 0.00 & 0.00 & 2.00 & 0.00 & 0.00 & 0.00 \\
\hline
\end{tabular}

Numbers in heading indicate the number of averaged analyses. Abbreviations: Exs = exsolutions; Grain bd $=$ grain-boundary; $\mathrm{mj}=$ majorite; B.D. = below the detection limits. Cation proportions based on 6 (for $\mathrm{cpx}$ and opx). 12 (for grt) and 11 (for phl) oxygens. 
Table DR 2. Average LA ICP MS analyses of trace element compositions of M3 minerals. Values in ppm.

\begin{tabular}{|c|c|c|c|c|c|c|c|c|c|}
\hline & cpx & M3 opx & M3 grt & M3 grt & & M3 grt & M3 Phl & M3 Mj & M1-M2 Mj \\
\hline ain bd & exs in M2 opx & grain bd & grain bd no exs & ain bd + exs & n no exs & ain bd + exs & grain bd 1 & $1.5 \%$ vol px & $20 \%$ vol px \\
\hline 8 & 2 & 8 & 11 & 5 & 3 & 3 & 11 & & \\
\hline 13.49 & 20.75 & 3.27 & 2.83 & 3.12 & 6.41 & 6.15 & 25.79 & & \\
\hline 0.73 & $<2.757$ & 0.497 & 0.84 & 0.98 & 1.15 & 1.04 & 1.04 & & \\
\hline 0.05 & $<0.026$ & 0.01 & 0.040 & 0.015 & 0.004 & 0.004 & 4.74 & & \\
\hline 0.99 & 0.05 & 0.54 & 0.27 & 0.40 & 0.04 & 0.011 & 421 & & \\
\hline 16.15 & 7.45 & 6.75 & 0.34 & 0.74 & 0.63 & 0.38 & 5944 & & \\
\hline 401 & 274 & 397 & 65 & 40 & 14.0 & 11.8 & 91482 & & \\
\hline 3.56 & 3.61 & 0.04 & 0.30 & 1.46 & 0.29 & 0.25 & 6.07 & & \\
\hline 0.20 & 0.20 & 0.08 & 0.039 & 0.092 & 0.051 & 0.07 & 0.11 & & \\
\hline 0.08 & 0.12 & 0.03 & 0.024 & 0.075 & 0.021 & 0.11 & 0.20 & & \\
\hline 0.11 & 0.14 & 0.04 & 0.048 & 0.055 & 0.043 & 0.05 & 15.85 & & \\
\hline 17.78 & 33.16 & 9.83 & 115 & 103 & 124 & 117 & 24 & & \\
\hline 11.69 & 20.06 & 0.14 & 0.055 & 0.702 & 0.060 & 0.41 & 0.12 & 0.53 & 0.03 \\
\hline 30.5 & 52.1 & 0.25 & 0.28 & 1.70 & 0.32 & 0.99 & 0.17 & 1.18 & 0.04 \\
\hline 3.60 & 5.76 & 0.02 & 0.10 & 0.21 & 0.16 & 0.20 & 0.008 & 0.22 & 0.01 \\
\hline 276 & 274 & 0.28 & 0.13 & 2.15 & 1.98 & 1.21 & 64.4 & & \\
\hline 13.58 & 19.36 & 0.05 & 1.03 & 1.24 & 1.56 & 1.70 & 0.034 & 1.87 & 0.22 \\
\hline 12.71 & 15.89 & 0.24 & 15.46 & 18.74 & 14.55 & 18.30 & 3.62 & & \\
\hline 1.67 & 2.04 & 0.08 & 0.69 & 0.70 & 0.81 & 0.71 & $<0.30$ & 0.77 & 1.16 \\
\hline 0.38 & 0.53 & $<0.02$ & 0.32 & 0.31 & 0.33 & 0.33 & 0.038 & 0.33 & 2.29 \\
\hline 497 & 10.02 & 73 & 199 & 145 & 281 & 267 & 25384 & & \\
\hline 0.64 & 0.83 & $<0.07$ & 0.96 & 1.00 & 0.90 & 0.92 & 0.027 & 0.82 & 3.23 \\
\hline 0.057 & 0.065 & $<0.009$ & 0.18 & 0.19 & 0.18 & 0.18 & 0.001 & 0.18 & \\
\hline 0.21 & 0.32 & $<0.01$ & 1.21 & 1.33 & 1.10 & 1.24 & $<0.148$ & 1.17 & 8.11 \\
\hline 0.65 & 0.89 & 0.01 & 7.59 & 8.86 & 7.39 & 8.04 & 0.19 & 7.35 & 9.97 \\
\hline 0.047 & $<0.118$ & $<0.01$ & 0.87 & 1.07 & 0.89 & 0.90 & $<0.15$ & 0.89 & 13.71 \\
\hline 0.034 & 0.17 & 0.01 & 1.15 & 1.31 & 1.13 & 1.15 & $<0.21$ & 1.11 & 18.51 \\
\hline
\end{tabular}

$<$ Value represents the limit of detection calculated using the 3 sigma criterion. Numbers in headings indicate the number of averaged analyses. Abbreviations: Grain bd: grain boundary mineral phase; Exs: exolution; Graind bd no exs: M3 grain boundary garnet without px needles; Grain bd + exs: M3 grain boundary garnet + pyroxene needles; Mj: majoritic garnet; B.D. = below the detection limits. M3 Mj and M1-M2 mj in the last columns are the reconstructed REE compositons of majoritic garnets based on the estimated amount of dissolved pyroxene (1.5 vol\% in M3 mj and 20 vol\% in M1-M2 mj. see methods). 
Table DR3. Partition coefficients between M3 phloogpite and the coexisting solid and fluid phases

\begin{tabular}{lrrr}
\hline & D phl / grain bd cpx & D phl / grt + exs & D phl / calc fl \\
$\mathrm{Li}$ & 1.91 & 4.19 & 2.22 \\
$\mathrm{~B}$ & 1.43 & 1 & 0.08 \\
$\mathrm{Cs}$ & 101 & 1067 & 1.66 \\
$\mathrm{Rb}$ & 426 & 37184 & 14.37 \\
$\mathrm{Ba}$ & 368 & 15730 & 34.29 \\
$\mathrm{~K}$ & 228 & 7778 & \\
$\mathrm{~Pb}$ & 1.70 & 23.83 & 0.19 \\
$\mathrm{Th}$ & 0.54 & 1.50 & 0.01 \\
$\mathrm{U}$ & 2.51 & 1.76 & 0.16 \\
$\mathrm{Nb}$ & 139 & 291 & 89 \\
$\mathrm{P}$ & 1.35 & 0.20 & \\
$\mathrm{La}$ & 0.01 & 0.28 & 0.002 \\
$\mathrm{Ce}$ & 0.01 & 0.17 & 0.005 \\
$\mathrm{Sr}$ & 0.23 & 53 & 0.14 \\
$\mathrm{Nd}$ & 0.003 & 0.02 & 0.002 \\
$\mathrm{Zr}$ & 0.28 & 0.20 & 0.12 \\
$\mathrm{Ti}$ & 51 & 95 & 68 \\
\hline
\end{tabular}




\section{Analytical methods.}

Major elements: Mineral major-element compositions were determined by electron probe microanalysis (EPMA) at Milano and Utrecht Universities (JEOL 8200 Super Probes, $15 \mathrm{kV}, 15 \mathrm{nA}$ beam current), in wavelength-dispersive spectrometry mode. A PhiRhoZ routine was used for matrix correction. Natural silicates were used as standards.

Trace elements: Trace element analyses were conducted by LA-ICP-MS with a Geolas Pro 2006 $193 \mathrm{~nm}$ ArF excimer laser coupled to an Elan DRC-e ICPMS instrument at the University of Bern, using instrumental conditions similar as reported in Pettke et al. (2004). Pit sizes were chosen as large as possible (up to $120 \mu \mathrm{m}$ diameter) to lower the limits of detection. External standardization was against the NIST SRM610 glass, and internal standardization used element concentrations determined by EPMA. Because LA-ICPMS analyses a cylindric volume (here $120 \mu \mathrm{m}$ diameter and $60 \mu \mathrm{m}$ deep), bulk majoritic trace element contents are direct measurements, quantified using reconstituted $\mathrm{Ca}$ concentrations (see below). Entire polyphase inclusions were drilled out of the host grt, and the data reduced using the approach developed for crystallized melt inclusions (Halter et al., 2002; Pettke et al., 2004). The mixed inclusion + host signal were unmixed by assuming an inclusion-to-host mass ratio between 0.25 and 0.4 , owing to the lack of a reliable estimate on a bulk inclusion element concentration. We note that this poses no limitations on the reliability of inclusion data for elements that are rare in the host (e.g., FIG. 3D), notably for normalized spider diagrams. Elements that are relatively enriched in the grt are highly susceptible to this host mineral correction; hence, these were not used for our data interpretation.

Reconstitution of majorite bulk composition: Bulk majoritic grt compositions reported in Table 1 were derived from BSE images of the M3 garnets hosting pyroxene needles, processed to estimate the volume abundances of the exsolved phases. Scanning electron microscopy was performed at the University of Genova using a Philips SEM 515 electron microscope. The ratios of surfaces covered by the needles and by the host were analysed on the compostitional grey-scale contrast. For M3 majoritic garnet, the estimated volume \% of originally dissolved pyroxene is 1 to 1.5 , cpx/opx ratio is $4 / 1$. The pre-exsolution major-element composition of M3 majorite was calculated using the measured compositions of needle-free M3 grt, of opx and cpx needles (Table 1) and the 1.5 volume\% pyroxene estimate $\left(\mathrm{grt}_{98.5} \mathrm{cpx}_{1.2} \mathrm{opx}_{0.3}\right)$. Calculations assumed that the area percentage equals the volume percentage of exsolved phases. Used mineral densities: grt $3.71 \mathrm{~g} / \mathrm{cm}^{3} ; \mathrm{cpx} 3.22 \mathrm{~g} / \mathrm{cm}^{3} ;$ opx $3.25 \mathrm{~g} / \mathrm{cm}^{3}$. The same volume proportions and densities have been used to calculate the pre-exsolution REE composition of the M3 majorite (Table 2). For this calculation we used the REE compostions of M3 needle-free grt and of associated grain-boundary cpx. This because the several $\mu \mathrm{m}$ thin pyroxene needles did not allow for measurements at useful limits of detection. The results obtained from this calculation reasonably match the measured REE compositions of $\mathrm{M} 3 \mathrm{grt}+$ needles (Fig. 3C). The major element and REE compositions of original M1A majorite in Tables 1 and 2 are reconstituted. 